Voix et Images

voixetimages

\title{
Le Théâtre canadien-français. Évolution. Témoignage. Bibliographie
}

\section{Bernard Andrès}

Volume 2, numéro 2, décembre 1976

Paul Chamberland

URI : https://id.erudit.org/iderudit/200061ar

DOI : https://doi.org/10.7202/200061ar

Aller au sommaire du numéro

Éditeur(s)

Les Presses de l'Université du Québec

ISSN

0318-9201 (imprimé)

1705-933X (numérique)

Découvrir la revue

Citer cet article

Andrès, B. (1976). Le Théâtre canadien-français. Évolution. Témoignage.

Bibliographie. Voix et Images, 2(2), 284-286. https://doi.org/10.7202/200061ar d'utilisation que vous pouvez consulter en ligne.

https://apropos.erudit.org/fr/usagers/politique-dutilisation/ 


\section{Le Théâtre canadien-français.} Évolution. Témoignage. Bibliographie.

Dans ce monument de mille pages ${ }^{1}$, édifié par une centaine de collaborateurs (surtout universitaires), les amateurs et spécialistes de théâtre québécois trouveront quantité d'informations précieuses sur cette activité où Guy Beaulnes voit, dès l'Introduction au volume, "la conscience d'un peuple".

Une première section traite des “Origines »: du Théâtre de Neptune, de Lescarbot, à L. Fréchette, en passant par T. Quesnel, Gérin-Lajoie et Pierre Petitclair. Baudoin Burger rappelle le type de spectacles présentés sous le régime français, tant dans les collèges de jésuites, que sous l'initiative d'officiers militaires. John Hare dresse pour sa part un «Panorama des spectacles au Québec: de la Conquête au XXe siècle ». 
Une deuxième partie regroupe une quinzaine d'études, sous le titre "Vers une tradition théâtrale". De nouvelles orientations se dessinent, tant à Montréal qu'à Québec, chez les amateurs comme chez les premiers professionnels. On s'interroge sur les pièces d'inspiration nationaliste, ainsi que sur les influences de Molière, de Shakespeare ou de la dramaturgie américaine. Une approche des «techniques théâtrales des dramaturges québécois" est tentée par Maximilien Laroche. Hélène Beauchamp-Rank dresse un bilan de "la vie théâtrale à Montréal, de 1950 à 1970 "; Renée Legris et Pierre Pagé en font autant de la production radiophonique et télévisée, des années trente à soixante. Ce sont les “orientations récentes du théâtre québécois" qui arrêtent l'attention de Laurent Mailhot. II faut enfin signaler - pour justifier le «canadien-français» du titre? - quatre études sur le théâtre de langue française dans l'Outaouais, au NouveauBrunswick et au Manitoba.

Dans les «Profils d'auteurs dramatiques», l'analyse porte sur des corpus plus spécifiques, centrés sur des auteurs-jalons: G. Gélinas, P. Toupin, M. Dubé, J. Languirand, F. Loranger, A. Hébert, M. Tremblay et J. Ferron.

Ce sont ensuite des études ponctuelles sur une dizaine de pièces (de, notamment: Claire Martin, Roch Carrier, Marie-Claire Blais, Guy Dufresne, Robert Gurik, Jean-Claude Germain et Antonine Maillet).

L'avant-dernière section est une vaste "enquête littéraire " d'Hélène Beauchamp-Rank. Une cinquantaine d'écrivains, metteurs en scène, comédien(ne)s, décorateurs, costumiers et musiciens, répondent à cinq questions: sur la notion du théâtre, "reflet" de la société, sur l'aspect de l'œuvre privilégié ou préféré par chacun d'eux, sur leurs projets et «le sens qu'ils aimeraient voir donner à leur œuvre". Malgré l'intention d'éviter le "who's who?", ces deux cents pages tournent plutôt à la galerie de portraits, à quelques exceptions près où l'on coupe vertement court au cabotinage et au bla-bla: "ces questions m'ennuient [...] Pensezvous qu'une poule se préoccupe de savoir si l'œuf qu'elle vient de pondre est un reflet de son milieu? Mon affaire est de pondre, je ponds. Libre aux amateurs d'omelettes de décider si mes œufs correspondent à leur attente ou pas! » (F. Loranger)

Les cinquante pages de la dernière partie: “Bibliographie», seront bien plus utiles au chercheur: John Hare y distingue les grandes bibliographies, les recueils et anthologies, les études générales, les documents sur les théâtres, troupes et comédiens, et sur la dramaturgie. Un index des pièces de théâtre dans l'ordre alphabétique des noms d'auteurs clôture 
enfin cette brique dont je n'ai certes pas la prétention d'avoir pu rendre justice en ce trop bref́ survol.

\section{Bernard Andrès}

1. Archives des lettres canadiennes, tome $Y$. Publication du Centre de recherche en civilisation canadienne-française de I'Université d'Ottawa, sous la direction de Paul Wyczynski, Bernard Julien et Hélène Beauchamp-Rank. Montréal, Fides, 1976,1005 pages. 